Bangladesh J. Bot. 41(2): 149-154, 2012 (December)

\title{
COMPARATIVE KARYOTYPE AND RAPD ANALYSIS FOR CHARACTERIZING THREE VARIETIES OF LYCOPERSICON ESCULENTUM MILL.
}

\author{
Sheikh Shamimul Alam*, Elham Ishrat, Md Yahia Zaman \\ and Md Ahashan Habib \\ Department of Botany, University of Dhaka, Dhaka-1000, Bangladesh
}

Key words: Karyotype, RAPD, Lycopersicon esculentum

\begin{abstract}
Three tomato varieties (Lycopersicon esculentum Mill.) viz. BARI tomato-11, BARI tomato-2 and BARI tomato-3 released from Bangladesh Agriculture Research Institute (BARI) were characterized by karyotype analysis and RAPD markers. BARI tomato-11 and BARI tomato-2 were found to possess $2 \mathrm{n}=24$ metacentric chromosomes. On the other hand, $2 n=25$ metacentric chromosomes were observed in BARI tomato-3 revealing a trisomic variety. The karyotype of the three varieties was very symmetric and each of the varieties showed specific and unique RAPD fingerprinting. Therefore, based on karyotype and RAPD analysis the three tomato varieties could be characterized.
\end{abstract}

\section{Introduction}

Tomato (Lycopersicon esculentum Mill.) is one of the most important vegetables, native of Central and South America. It is extensively cultivated throughout the world. It is eaten as raw or cooked in salads and used sauces, soups and meat or fish dishes as flavouring agents (Ahmed et al. 2009).

Bangladesh Agriculture Research Institute (BARI) has made several breeding programmes to create variability for transferring desirable characters such as fruit size, colour, disease resistance, etc. for the development of suitable tomato variety. As a result, 15 varieties and 8 hybrid varieties of tomato were released by BARI (Md. Shahidul Islam, BARI, Personal communication 2012). These varieties are characterized solely by morphological features. No genomic information about these varieties is available. Genetic information has been considered as an important factor and pre-requisite for plant improvement programme (Chaudhuri et al. 1976). Therefore, detailed genetic information of the available varieties of tomato is necessary for proper identification and characterization.

It is well established that cultivated tomato is a diploid with $2 \mathrm{n}=2 \mathrm{x}=24$ chromosomes (Rick 1960, Haskell 1964, Bose and Banerjee 1968). In a few varieties/races, $2 n=25$ chromosomes (trisomic) were also reported (Chaney and Reeves 1973, Gill 1978). Generally, trisomic produces half of the sterile gametes $(n+1)$ due to irregular distribution of chromosomes at anaphase. This type of gametes generally does not participate in fertilization. Therefore, a screening is necessary prior to release the variety to the farmers. Moreover, the varieties released from BARI should be characterized genomically to prevent the trade piracy.

Karyotype of a variety is a stable character and often play role to distinguish different taxa. However, the problem arises when different taxa possess same chromosome number and centromeric position. In such a situation, other karyotype features like total length of $2 \mathrm{n}$ chromosome complements and range of individual chromosome length might help in this regard.

*Author for correspondence: <ssalam81@yahoo.com>. 
In addition molecular characterization is more reliable and authentic. In recent years, Random Amplified Polymorphic DNA (RAPD) analysis through the Polymerase Chain Reaction (PCR) has been widely used in molecular characterization and trace the phylogeny of diverse plant and animal species. This technique has contributed widely in the studies of genetic diversity and phylogenetic analysis (Savolainen and Chase 2003, Nybom 2004). These markers are used as versatile tools to provide the correct estimate of genetic diversity. The main advantages of RAPD analysis over other molecular methods are low sample DNA requirements, the high frequency of detectable polymorphic bands (Williams et al. 1990) and independent from the effects of environmental factors (Powell et al. 1995, Garcia et al. 1998, Kuras et al. 2004).

In this study, three tomato varieties released from BARI were considered to - (a) confirm diploid chromosome number of the varieties, (b) elucidate aneuploidy or other chromosomal aberration and (c) characterize the varieties based on karyotypic analysis and RAPD fingerprinting.

\section{Materials and Methods}

Three varieties of tomato namely, (i) BARI tomato-11 (Jhumka), (ii) BARI tomato-02 (Ratan) and (iii) BARI tomato-03 were used in this study (Figs a - c). These varieties were collected from BARI and maintained in the Botanical Garden, Department of Botany, University of Dhaka, Bangladesh.

Healthy roots of the grown plants from the field were collected and pretreated with $0.002 \mathrm{M}$ 8-hydroxyquinoline for $30 \mathrm{~min}$ at $18^{\circ} \mathrm{C}$ followed by $15 \mathrm{~min}$ fixation in $45 \%$ acetic acid at $4^{\circ} \mathrm{C}$. These were then hydrolysed in a mixture of $1 \mathrm{~N} \mathrm{HCl}$ and $45 \%$ acetic acid $(2: 1)$ at $60^{\circ} \mathrm{C}$ for $8 \mathrm{~s}$. The root tips were stained and squashed in $1 \%$ aceto-orcein.

Tender leaves were harvested and total genomic DNA was extracted by using modified CTAB method (Doyle and Doyle 1987). DNA concentration was quantified through spectrophotometer (Analylikjena, Specord 50, Germany).

The PCR reaction mixture for $25 \mu$ contained template DNA (25 ng) $2 \mu \mathrm{l}$, de-ionized distilled water $18.8 \mu \mathrm{l}$, Taq buffer A $10 \times$ (Tris with $\left.15 \mathrm{mM} \mathrm{MgCl}_{2}\right) 2.5 \mu \mathrm{l}$, primer $(10 \mu \mathrm{M}) 1.0 \mu \mathrm{l}$, dNTPs $(2.5 \mathrm{mM}) 0.5 \mu \mathrm{l}$ and Taq DNA polymerase (5U/ $\mu \mathrm{l}) 0.2 \mu \mathrm{l}$. PCR amplification was done in an oilfree thermal cycler (Biometra UNOII, Germany) for 46 cycles after initial denature at $94^{\circ} \mathrm{C}$ for 5 min, denature at $94^{\circ} \mathrm{C}$ for $1 \mathrm{~min}$, annealing at $36^{\circ} \mathrm{C}$ for $30 \mathrm{~s}$, extension at $72^{\circ} \mathrm{C}$ for $3 \mathrm{~min}$ and final extension at $72^{\circ} \mathrm{C}$ for $5 \mathrm{~min}$. Six primers of Operon Technologies, USA viz. Batch-7736-030 (GAA ACG GGT G), Batch-7736-031 (GTT GCG ATC C), Batch-7736-032 (TGC CGA GCT G), Batch-7736-033 (GGG TAA CGC C), Batch-7736-034 (TCA CGT CCA C) and Batch- 7736036 (CCC GCC TTC C) series were used.

The amplified products were separated electrophoretically on $1 \%$ agarose gel. The gel was prepared using $1.0 \mathrm{~g}$ agarose powder containing ethidium bromide $(10 \mathrm{mg} / \mathrm{ml}) 8 \mu \mathrm{l}$ and $100 \mathrm{ml} 1 \times$ TAE buffer. Agarose gel electrophoresis was conducted in $1 \times$ TAE buffer at 50 volts and $100 \mathrm{~mA}$ for $1.5 \mathrm{~h}$. DNA ladder $(1 \mathrm{~kb})$ was electrophoresed alongside the RAPD reactions as marker. DNA bands were observed on UV-transilluminator and photographed by a gel documentation system.

The PCR products were analyzed after gel electrophoresis. The photographs were critically examined on the basis of presence (1) or absence (0), size of bands and overall polymorphism of bands. These were carried out for further investigation. RAPD analysis was then combined to create a single data matrix. This was used for estimating linkage distance (D) and constructing a UPGMA (Unweighted Pair Group Method of Arithmetic Means) dendrogram among the varieties using computer program "Statistica". Linkage distances were computed from frequencies of polymorphic markers to estimate genetic relationship between the studied three tomato varieties using UPGMA (Sneath and Sokal 1973). 


\section{Results and Discussion}

BARI tomato-11 and BARI tomato-2 were found to possess $2 \mathrm{n}=24$ metacentric chromosomes (Figs 1d - e, Table 1). Same 2n chromosome number was reported earlier in tomato (Rick 1960, Haskell 1964, Bose and Banerjee 1968). On the other hand, $2 \mathrm{n}=25$ metacentric chromosomes were found in BARI tomato-3 (Fig. 1f, Table 1). The extra chromosome was the smallest and a regular number of pair XII (Table 1). It suggested that this variety is a primary trisomic. Trisomic in tomato was reported earlier (Chaney and Reeves 1973, Gill 1978). However, trisomoic tomato (BARI tomato-3) is a new report for BARI tomato variety. The trisomic variety was also karyotypically different from the rest two varieties in respect of - (i) the range of individual chromosome length $(0.41-0.75 \mu \mathrm{m})$ was the lowest among three varieties (Table 1) and (ii) total length of $2 \mathrm{n}$ chromosome complements $(14.11 \mu \mathrm{m}$, Table 1). Therefore, karyotypically BARI tomato-3 is different from the rest two.

Table 1. Karyotypic characterization of three varieties of Lycopersicon esculentum.

\begin{tabular}{ccccc}
\hline Varieties & $2 \mathrm{n}$ & $\begin{array}{c}\text { Range of } \\
\text { chromosomal } \\
\text { length }(\mu \mathrm{m})\end{array}$ & $\begin{array}{c}\text { Total length of 2n } \\
\text { chromosome } \\
\text { complement }(\mu \mathrm{m})\end{array}$ & $\begin{array}{c}\text { Karyotype } \\
\text { formulae }\end{array}$ \\
\hline BARI tomato-11 & 24 & $0.58-1.05$ & 17.10 & $24 \mathrm{~m}$ \\
BARI tomato-02 & 24 & $0.63-1.17$ & 19.99 & $24 \mathrm{~m}$ \\
BARI tomato-03 & 25 & $0.41-0.75$ & 14.11 & $25 \mathrm{~m}$ \\
\hline
\end{tabular}

$\mathrm{m}=$ Metacentric chromosome.

The three varieties had all metacentric chromosomes (Figs 1d - f, Table 1). The difference between smallest and biggest chromosomes was almost $0.5 \mu \mathrm{m}$ only (Table 1). As a result, no gradual decrease in chromosomal length was observed. These are the characteristic features of strict symmetric karyotype. Some other members of the genus Solanum e.g., S. vilossum, S. americanum and $S$. melongena have moderately symmetric karyotype a few sub-metacentric chromosomes are present in their karyotypes (Sultana and Alam 2007, Fawzia and Alam 2011). Symmetric karyotype is primitive in nature (Stebbins 1971). Therefore, tomatoes are primitive than these species of Solanum.

RAPD analysis revealed no band in BARI tomato-3 in primer batch-7736-031, 7736-034 and 7736-036 (Figs 1h, k, l). This result suggested the absence of those sequences in BARI tomato-3. In primer combination 7736-030, two fragments of 1000 and 700 bp were common in all the three varieties (Fig. 1g). This revealed that the three varieties are sharing some common fragments of genome.

In spite of a few common bands, each variety showed specific characteristic RAPD fingerprinting. These bands were unique and not present in other varieties. For example, a fragment of 1700 and 2300 bp was found in primer 7736-030 in BARI tomato-11 and BARI tomato-3, respectively (Fig. 1g). In primer 7736-032, fragment size of 1200 and 300 bp were found in only BARI tomato-11. Two bands of 2400 and 1700 bp were found in only BARI tomato-2 in the same primer (7736-032, Fig. 1i). BARI tomato-11 showed a band of 1000 bp in primer 7736-033 which was absent in other two varieties (Fig. 1j). Two fragments of 2500, $1200 \mathrm{bp}$ and one of $5000 \mathrm{bp}$ were found in BARI tomato-11 and BARI tomato-2, respectively with primer 7736-034 (Fig. 1k). BARI tomato-11 showed a band of 5000 bp in primer 7736-036 which was absent in other two varieties (Fig. 11). 

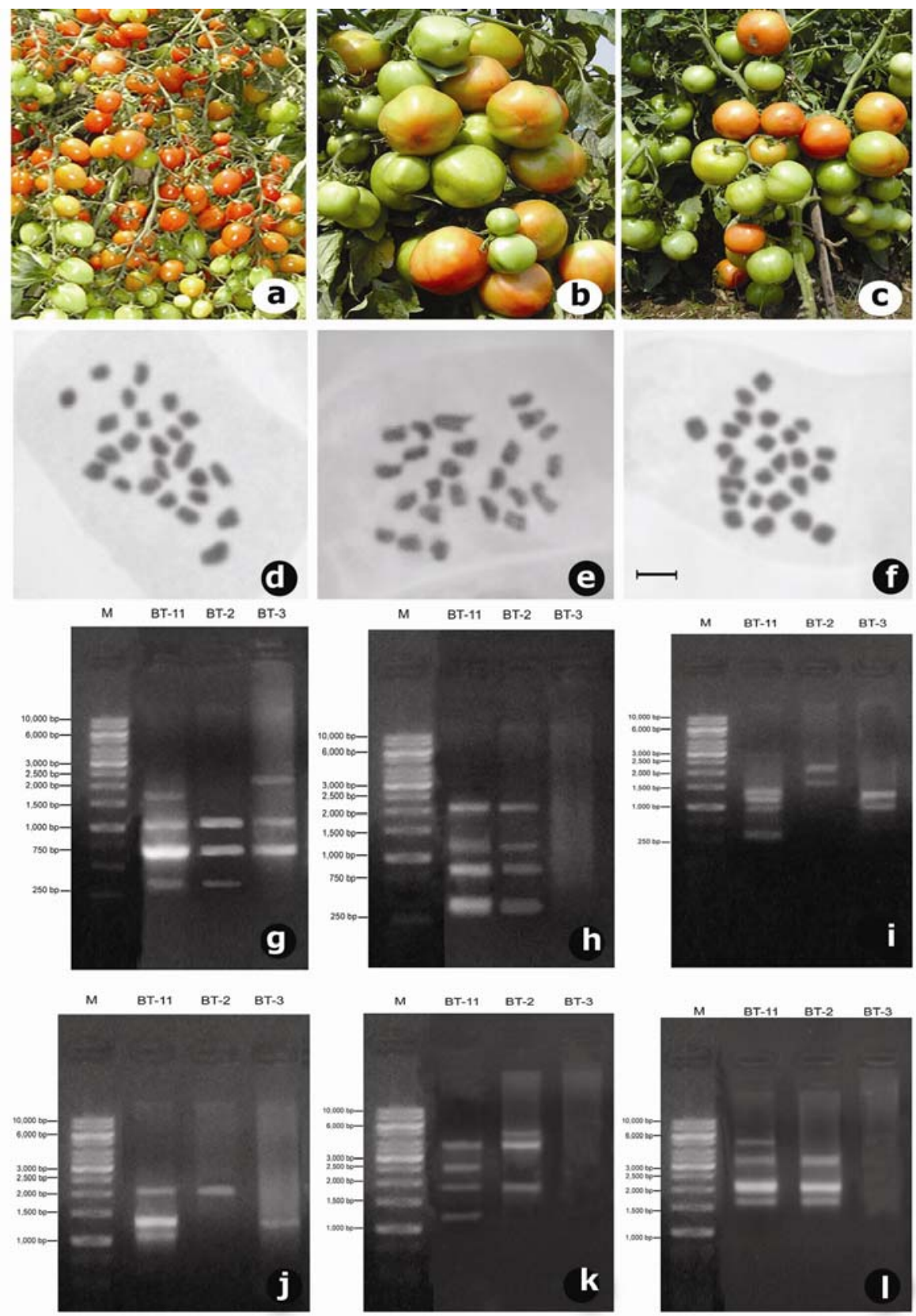

Figs 1a - l. Morphology and comparative cytogenetical and molecular analysis of three varieties of Lycopersicon esculentum. a, BARI tomato-11 (Jhumka); b, BARI tomato-02 (Ratan); c, BARI tomato03, d, e and f, Orcein-stained mitotic metaphase chromosomes of BARI tomato-11 (Jhumka), BARI tomato-02 (Ratan), BARI tomato-03, respectively $(\mathrm{Bar}=1 \mu \mathrm{m})$; g, RAPD analysis with Primer Batch7736-030; h, RAPD analysis with Primer Batch-7736-031; i, RAPD analysis with Primer Batch-7736032; j, RAPD analysis with Batch-7736-033; k, RAPD analysis with Primer Batch-7736-034 and l, RAPD analysis with Primer Batch- 7736-036. 
The dendrogram tree showed that on the basis of the cluster analysis, BARI tomato-11 and BARI tomato-2 were placed in a cluster at linkage distance 13. BARI tomato-3 was placed in another cluster far away form the first cluster at linkage distance 17.5 (Fig. 2). Therefore, the three varieties could easily be identified with the help of cluster analysis.

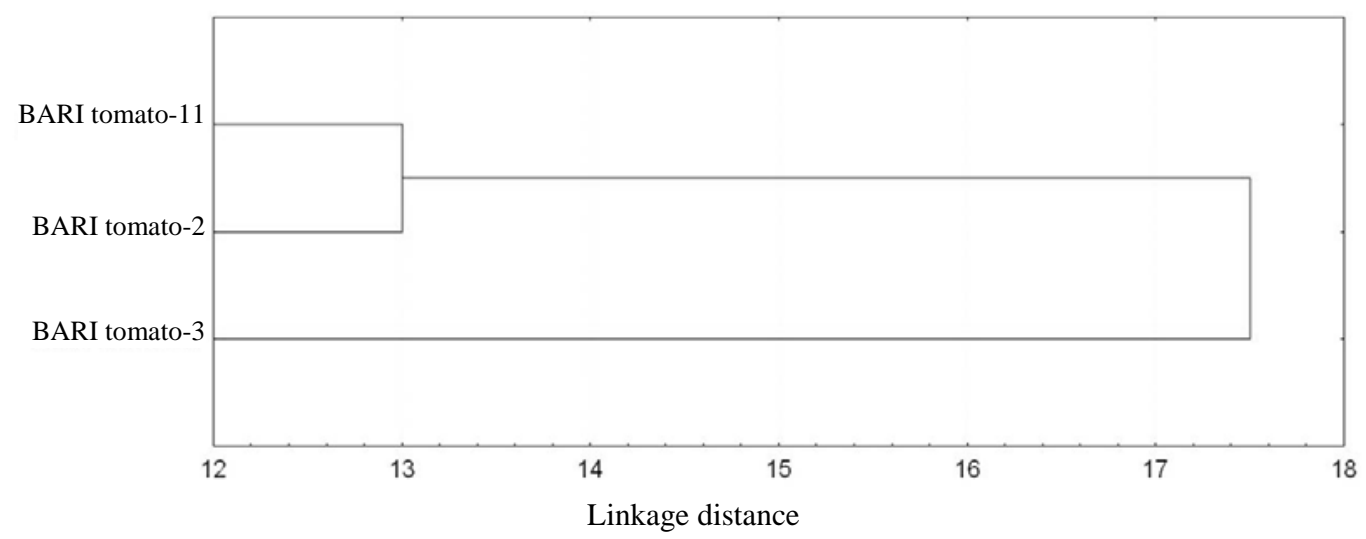

Fig. 2. Cluster analysis by UPGMA of three varieties in Lycopersicon esculentum Mill. based on different RAPD markers.

The above results showed that BARI tomato- 3 is quite different from the rest two varieties of tomato in respect to - (i) $2 n=25$ chromosome instead of $2 n=24$, revealing a trisomic nature (Fig. 1c). (ii) lowest total length of $2 \mathrm{n}$ chromosome complement $(14.25 \mu \mathrm{m})$ and range of individual chromosome length $(0.75-0.41 \mu \mathrm{m})$ (Table 1), (iii) no RAPD fragment was found in primer batch 7736-031, 7736-034 and 7736-036 (Figs 1h, k, l), (iv) showed characteristic specific bands in primer 7736-030 and 7736-034 (Figs 1g, k) and (v) the tree dendrogram showed that this variety was placed in different cluster far away from other two varieties at linkage distance 17.5 (Fig. 2).

With the help of above parameters, BARI tomato-3 could be easily characterized. This variety is a primary trisomic. Trisomic produces unbalanced gametes due to irregular distribution of chromosomes at anaphase and generally resulting in $50 \%$ sterile gametes. This lowers the yield of BARI tomato-3. Therefore, BARI authority must characterize tomato varieties before releasing those to the farmers.

\section{References}

Ahmed ZU, Hassan MA, Begum ZNT, Khondker M, Kabir SMH, Ahmad M and Ahmed ATA (Eds) 2009. Encyclopedia of Flora and Fauna of Bangladesh, Vol. 10. Angiosperms: Dicotyledons (RannunculaceaeZygophyllaceae). Asiatic Society of Bangladesh, Dhaka. pp. 580.

Bose S and Banerjee B 1968. Effect of treatments of X-rays and colchicines on tomato. The Nucleus 11: 160169.

Chaney LA and Reeves AF 1973. Chromosome pairing in tomato tertiary trisomics. Can. J. Genet. Cytol. 15: 327-329.

Chaudhuri BK, Chaudhuri SK, Basak SL and Dana S 1976. Cytogenetics of a cross between two species of annual Crysanthemum. Cytologia 41: 111-121. 
Doyle JJ and Doyle JL 1987. A rapid DNA isolation procedure from small quantities of fresh leaf tissues. Phytochemical Bulletin 19: 11-15.

Fawzia R and Alam SSk 2011. Fluorescent karyotype analysis in four varieties of Solanum melongena L. Cytologia 76(3): 345-351.

Garcia E, Jamilena M, Alvarez JI, Arnedo T, Oliver JL and Lozano R 1998. Genetic relationships among melon breeding lines revealed by RAPD markers and agronomic traits. Theo. Apply. Genet. 96: 878885.

Gill BS 1978. Cytogenetics of an unusual tertiary trisomic of tomato. Caryologia 31: 257-269.

Haskell G 1964. An unusual sport in tomato. J. R. Hortic. Soc. 89: 504.

Kuras A, Korbin M and Zurawicz E 2004. Comparison of suitability of RAPD and ISSR techniques for determination of Strawberry (Fragaria $\times$ Ananassa Duch.) relationship. Plant Cell Tiss. Organ Cult. 79: 189-193.

Nybom H 2004. Comparison of different nuclear DNA markers for estimating intraspecific genetic diversity in plants. Mol. Ecology 13: 1143-1155.

Powell W, Orozco-Castillo C, Chalmers KJ, Provan J and Waugh R 1995. Polymerase chain reaction based assays for the characterization of plant genetic resources. Electrophoresis 16: 1726-1730.

Rick CM 1960. Hybridization between Lycopersicon esculentum and Solanum pennellii : Phylogenetic and cytogenetic significance. Proc. Natl Acad. Soc. USA 46(1): 78-82.

Savolainen V and Chase MW 2003. A decade of progress in plant molecular phylogenetics. Trends in Genetics 19: 717-724.

Sneath PHA and Sokal RR 1973. Numerical taxonomy. W.H. Freeman and Co., San Francisco, CA. pp. 2128.

Stebbins GL 1971. Chromosomal evolution in higher plants. Addison-Wesley Publishing Company, California. pp. 208.

Sultana SS and Alam SSk 2007. Differential fluorescent chromosome banding of Solanum nigrum L. and Solanum villosum L. from Bangladesh. Cytologia 72: 213-219.

Williams JGK, Kubelik AR, Livak KJ, Rafalski JA and Tingey SV 1990. DNA polymorphisms amplified by arbitrary primers are useful as genetic markers. Nucleic Acids Res. 18: 6531-6535.

(Manuscript received on 20 June, 2012; revised on 16 September, 2012) 